\title{
THE EFFECTS OF ANTIBIOTIC PROPHYLAXIS ON INFECTIOUS COMPLICATIONS AFTER CAESAREAN SECTION: A RANDOMISED CONTROLLED TRIAL IN A TERTIARY HOSPITAL OF EASTERN INDIA
}

Shelley Seth, Sharmistha Banerjee, Sanjoy Mukherjee, Aparna Chakraborty, Udayan Mitra, Joydip Paul

\footnotetext{
1. Assistant Professor. Department of Obstetrics \& Gynaecology, College of Medidine \& Sagore Dutta. Hospital, Kamarhati, Kolkata.

2. Assistant Professor. Department of Obstetrics \& Gynaecology, College of Medidine \& Sagore Dutta. Hospital, Kamarhati, Kolkata.

3. RMO cum Clinical Tutor. Department of Obstetrics \& Gynaecology, RG Kar Medical College \& Hospital, Kolkata.

4. RMO cum Clinical Tutor. Department of Obstetrics \& Gynaecology, College of Medicine \& Sagore Dutta. Hospital, Kamarhati, Kolkata.

5. Specialist Medical Officer. Department of Obstetrics \& Gynaecology, Aliporeduar, SD Hospital.

6. RMO cum Clinical Tutor. Department of Obstetrics \& Gynaecology, College of Medicine \& Sagore Dutta. Hospital, Kamarhati, Kolkata.
}

\section{CORRESPONDING AUTHOR:}

Dr. Shelley Seth,

26/1B, Seven Tanks Lane,

Kolkata, PIN- 700030.

E-mail: seth_shelley@yahoo.com

ABSTRACT: CONTEXT: Infectious complications after caesarean deliveries are an important and substantial cause of maternal morbidity and increase in the hospital stay and cost of treatment. Routine prophylaxis with antibiotics may reduce this risk. AIMS: To determine whether prophylactic antibiotic administration using ceftriaxone at the time of caesarean section significantly reduces maternal and neonatal infectious complications. SETTINGS AND DESIGN: The study was conducted in a tertiary teaching hospital of eastern India during March 2011 to October 2011. It was a prospective, double-blind randomised placebo-controlled trial. METHODS AND MATERIAL: After exclusion due to different reasons, 288 patients were enrolled in study group and received prophylactic injection ceftriaxone. 293 patients were enrolled in control group who received placebo. Patients were randomly selected according to computerized randomization protocol. Postpartum infectious complications were recorded, as were the duration of hospital stay and neonatal complications. STATISTICAL ANALYSIS USED: Analysis of statistical data was done by using statistical software Open Epi, 8version 2.3.1. RESULTS: Wound indurations, discharge, erythema were $2.43 \%$ and $5.80 \%$ in study and control group respectively and it was statistically significant with $\mathrm{p}$ value 0.043 (RR=0.419, 95\% confidence interval [CI] 0.405. Endomyometritis was more in control group (1.04\% vs. 3.75\%) with $\mathrm{p}$ value 0.036 and $\mathrm{RR}=0.279$ and $\mathrm{CMLE} \mathrm{OR}=0.272$. No significant relationship with neonatal morbidities was found. Maternal stay in hospital was significantly more with $p=0.01$ in control group. CONCLUSIONS: Antibiotic prophylaxis prior to skin incision of caesarean sections resulted in better maternal outcome when infectious morbidity and postoperative hospital stay were concerned, without influencing the neonatal outcome.

KEY WORDS: Antibiotic prophylaxis, Caesarean deliveries, Infectious complications. 
MeSH TERMS: Antibiotic Prophylaxis, Cesarean Section/adverse effects, Endometritis/prevention \& control, Postoperative Complications/prevention \& control.

INTRODUCTION: To prevent any surgical infection, general principles to be followed are sound surgical technique, skin antisepsis and antimicrobialprophylaxis. ${ }^{1}$ Antibiotics administered prophylactically reduce the bacterial inoculum at the time of surgery and decrease the rate of bacterial contamination of the surgical site. Infectious complications following caesarean delivery include fever, wound infection, endometritis, urinary tract infection and some serious complications like pelvic abscess, septic shock, and septic pelvic vein thrombophlebitis. Antibiotic prophylaxis in women who undergo caesarean delivery has been proven to be beneficial in decreasing infectious morbidities both in high-risk women (eg, laboring, after rupture of membrane) ${ }^{2,3}$ and low-risk patients (eg, non-laboring, intact membranes)..2,4The goal of perioperative prophylaxis is to attain therapeutic levels of antibiotic agents in the tissues at the time of microbial contamination. ${ }^{5}$ Following elective surgery, wound infection in patients who receive peri-operative antibiotics (within three hours following skin incision) occurs in $1.4 \%$ compared with $0.6 \%$ in those who receive antibiotics within two hours prior to skin incision. ${ }^{6}$ The objective of our study were (i) to assess the effects of prophylactic antibiotics compared with no prophylactic antibiotics on infectious complications in women undergoing caesarean section. (Time Frame: 6 weeks) and (ii) to assess the incidence of neonatal infectious complications (i.e. rates of sepsis work-up, confirmed sepsis and length of hospital stay) between two study arms.

MATERIALS AND METHODS: This was a prospective, double-blind randomised controlled study. Among the patients admitted and selected for caesarean section delivery, at term, during March 2011 to October 2011, in the department of Obstetrics \& Gynaecology of R.G.Kar Medical College and Hospital, where annually around 18000 deliveries occur and around 35\% caesarean sections are performed. A minimum required sample size was calculated to be 278 in each arm (setting $\alpha$ at 0.05 and power at $80 \%$ (i.e. $\beta$ at 0.8 ).Initially 600 patients were enrolled for this study. Exclusion criteria were patients with obstetric complications (such as pre-eclampsia, ante partum hemorrhage), with renal disease, heart disease, diabetes mellitus etc., febrile during or prior to screening, with ruptured membranes and on antibiotic prophylaxis, contraindication to antibiotics administration (known anaphylactic reaction to penicillin or cephalosporin allergy), with exposure to antibiotic in one week prior to caesarean delivery, obstetrical indication for emergent caesarean delivery during labour e.g. non-progress of labor due to obstructed labor or deep transverse arrest or foetal distress. After exclusion due to different reasons, 288 patients in group A and 293 patients in group B completed study and analysed. Patients were randomly selected according to computerized randomization protocol. ${ }^{7}$ This study was approved by Ethics Committee of R.G.Kar Medical College and Hospital and all women gave informed consent.

Group A (Study group) received prophylactic antibiotics ceftriaxone [2gm] IV at least 30 minutes before skin incision. Group B (Control group) received no prophylactic antibiotic. The occurrence of endomyometritis, wound infection, total infectious morbidity, and neonatal complications were compared. Detailed history taking and clinical examination were carried out before caesarean section, during post- operative hospital stay and also at 6 week postpartum visit or earlier (assuming that in case of major morbidity, they would make hospital visit whenever required). Selective investigations were done when required, such as complete blood 
count, urine for RE/ME and urine for C/S, X-ray chest, USG of lower abdomen-pelvis, blood culture, vaginal swab culture, wound swab culture. To make the study double blinded the drugs were supplied in small sealed bag containing vial A (2gm ceftriaxone mixed with $10 \mathrm{ml}$ water for injection, antibiotic was dissolved just before administration by an independent third person who ultimately did not participate in final outcome) and Vial B ( $10 \mathrm{ml}$ water for injection as placebo). Both vials were identical. Registration numbers of the patients were mentioned over the bag. On duty resident doctor opened the supplied sealed bag at least 30 minutes prior to operation and after skin testing either vial A or vial B medicine was administered intravenously slowly according to randomization. Providers and patients were blinded to the contents of the bags. Caesarean sections were performed by resident medical officers, generally spinal anesthesia were given. Post-operative follow up was done by resident doctors who were blinded to the patients and babies identity. Infectious morbidity like endomyometritis was diagnosed if maternal fever greater than $100.4^{\circ} \mathrm{F}$ on two separate occasions along with uterine fundal tenderness, tachycardia, or leukocytosis. Wound infection was diagnosed if there was purulent discharge, erythema, and indurations of the incision site. Hematoma, seromas, or wound breakdowns in the absence of previously discussed signs were not considered wound infections. Pyelonephritis was diagnosed by maternal temperature, flank pain, and urine culture showing more than 100,000 colonies of a gram negative uropathogen. Neonatal sepsis was diagnosed by clinical examination, blood picture, $\mathrm{C}$ reactive protein estimation and positive blood culture as appropriate. Antibiotic resistance and clinical course data were recorded. Length of stay, admission status and decision to undertake a sepsis workup were determined by the staff neonatologist who were blinded to group assignment. Analysis of statistical data were done by standard statistical tools used for epidemiologic statistics by using statistical software Open Epi, ${ }^{8}$ version 2.3 .1 or its updated at the time of analysis. P value less than 0.05 was considered to be statistically significant.

RESULTS: In group A, 288 patients and in group B, 293 patients were analysed. Analysing the demographic pattern, no statistically significant data were found regarding age, BMI and gestational ages (Table 1). Mean gestational ages were $39.31 \pm 1.22$ in group A and $39.14 \pm 1.26$ weeks in group B. In group A, primigravida, 2nd gravida and 3rd gravida were $44.79 \%, 38.89 \%$ and $16.32 \%$ respectively. Whereas in group B these findings were $39.24 \%, 44.03 \%$ and $16.72 \%$ respectively (Table 2). Considering the indications for caesarean section, no statistically significant relation was found. Most common indications were history of previous CS in both study and control group i.e. $41.67 \%$ and $46.42 \%$ respectively (Table 3 ). There were more cases of wound indurations, discharge, erythema in control group than that in the study group and it was statistically significant with p value 0.043 ( $R R=0.419,95 \%$ confidence interval [CI] 0.405 . Incidence of endomyometritis in control group were more than that in the study group, and this difference was statistically significant with $p$ value 0.036 and $R R=0.279$ and CMLE $O R=0.272$ (Table 4). No significant relationship with neonatal morbidities was found (Table 5). Maternal stay in hospital was significantly more with $\mathrm{p}=0.01$ in control group (Table 6).

DISCUSSION: Caesarean section delivery is one of the most common major operation performed today and rates of complication of infection, including resultant increased cost and length of stay are higher than that for any other comparable surgery. In our study, we used single dose (2gm IV) broad-spectrum 3rd generation cephalosporin, injection ceftriaxone as an antibiotic prophylaxis. In our institution ceftriaxone is most commonly used following 
caesarean sections as it is easily available, cost effective and clinically useful. Various previous studies already established the inj. ceftriaxone as an antibiotic prophylaxis for caesarean section $^{2,9}$

In a systematic review of over 80 studies on the use of prophylactic antibiotics for caesarean sections, the Cochrane Collaboration specifically examined the effect of prophylactic antibiotics on the rate of maternal postpartum fever, wound infection, endometritis, urinary tract infection, serious infectious morbidity or death, as well as maternal side effects and length of hospital stay. For all caesarean deliveries (both elective and emergency) the only outcome which increased following prophylactic antibiotics was maternal side effects, though this did not reach statistical significance. For all of the other outcomes, the use of antibiotics was associated with a statistically significant reduction, with an effect size of 40-65\%. Endometritis and wound infections were reduced following both elective and emergency caesarean deliveries by $60-70 \%$ and $30-65 \%$ respectively. ${ }^{2}$

In our study considering postoperative maternal infectious morbidity, in Table 4, it was seen that the wound infections and endomyometritis incidence were less in study group. There were statistically significant more cases of wound indurations, discharge, erythema in control group ( $p=0.043)$. Cases of endomyometritis in control group were more than study group, and this difference was statistically significant $(p=0.036)$.

Whereas considering stay in NICU, it was more in control group but was not statistically significant ( $\mathrm{p}=0.901$ and $95 \%$ CI was -2.050 to 1.810$)$. Findings by other authors also correspond with it.10,11

From analysis of our present study it can be concluded that prophylactic antibiotic at least 30minutes before skin incision resulted in better maternal outcome when infectious complications and postoperative hospital stay were concerned, without influencing the neonatal outcome.

Limitations: It was not possible to choose the patients with uniform characteristics in all aspect. Apart from their age, BMI, gravida- parity, we could not compare the pharmacokinetics of antibiotics in individual patients. The number of candidates selected for emergency caesarean section was less than that of elective cases. During preoperative preparation, operative procedures, anesthesia, immediate postoperative management different persons were involved.

\section{REFERENCES:}

1. Owen J, Andrews WW. Wound complications after cesarean sections. Clinical ObstetGynecol1994;37:842-55.

2. Smaill F, Hofmeyr GJ. Antibiotic prophylaxis for cesarean section. Cochrane Database Syst Rev 2002:CD000933.

3. Gibbs RS, St. Clair PJ, Castillo MS, Castaneda YS. Bacteriologic effects of antibiotic prophylaxis in high-risk cesarean section .Obstet Gynecol 1981;57:277-82.

4. American College of Obstetricians and Gynecologists. Prophylactic antibiotics in labor and delivery: ACOG Practice Bulletin No.: 47. Washington (DC): The College; 2003.

5. Burke JF. The effective period of preventive antibiotic action in experimental incisions and dermal lesions. Surgery 1961;50:161-8.

6. Fiore Mitchell T, Pearlman MD, Chapman RL, Bhatt-Mehta V, Faix RG. Maternal and transplacental pharmacokinetics of cefazolin. Obstet Gynecol. 2001 Dec;98(6):1075-9.

7. Research Randomizer: Free Random Sampling and Random..www.randomizer.org/ Cached - Block all www.randomizer.org results. 
8. website: http://www.openepi.com.

9. Adam I, Adam ES, Gerais AS. Randomized trial of ceftriaxone prophylaxis in elective cesarean section. Saudi Med J. 2005 Mar;26(3):500-1.

10. Mugford M., Kingston J., Chalmers I..Reducing the incidence of infection after caesarean section: implications of prophylaxis with antibiotics for hospital resources.BMJ 1989;299: 1003-1006.

11. Green S.L., SarubbiF.A., Bishop E.H.. Prophylactic antibiotics in high risk caesarean section. Obstet Gynaecol 1978;51: 569-572.

Table 1: Patient demographics

\begin{tabular}{|llll|}
\hline & Study group A $\mathrm{n}=288$ & Control group B $\mathrm{n}=293$ & P value (Mid-P exact) \\
Mean age $\pm \mathrm{SD}$ & $25.21 \pm 4.21$ & $25.30 \pm 4.12$ & 0.923 \\
BMI & $24.17 \pm 3.42$ & $24.01 \pm 3.48$ & 0.475 \\
Gestational age in week: & $39.31 \pm 1.22$ & $39.14 \pm 1.26$ & 0.553 \\
\hline
\end{tabular}

Table 2: Gravidity of the patients

\begin{tabular}{|llll|}
\hline & Study group A n=288 & Control group B $\mathrm{n}=293$ & P value (Mid-P exact) \\
Primi gravida & $129(44.79 \%)$ & $115(39.24 \%)$ & 0.254 \\
2nd gravida & $112(38.89 \%)$ & $129(44.03 \%)$ & 0.135 \\
3rd gravida or more & $47(16.32 \%)$ & $49(16.72 \%)$ & 0.642 \\
\hline
\end{tabular}

Table 3: Indication for Caesarean sections

\begin{tabular}{|c|c|c|c|}
\hline & $\begin{array}{l}\text { Study group A } \\
\mathrm{n}=288\end{array}$ & $\begin{array}{l}\text { Control group B } \\
n=293\end{array}$ & $\begin{array}{l}\text { P value } \\
\text { (Mid-P exact) }\end{array}$ \\
\hline 1.Post C/S At Term & $120(41.67 \%)$ & $136(46.42 \%)$ & 0.206 \\
\hline 2.Elderly Primi gravida & $21(7.29 \%)$ & $19(6.48 \%)$ & 0.814 \\
\hline 3. Repeat C/S & $13(4.51 \%)$ & $12(4.10 \%)$ & 0.754 \\
\hline 4.H/O Myomectomy & $1(0.35 \%)$ & 0 & \\
\hline $\begin{array}{l}\text { 5.Term pregnancy with } \\
\text { CPD not in labor }\end{array}$ & $29(10.07 \%)$ & $23(7.85 \%)$ & 0.301 \\
\hline $\begin{array}{l}\text { 6.Post Term, Term (less fetal movement } \\
\text { \& non reassuring CTG) }\end{array}$ & $25(8.68 \%)$ & $22(7.51 \%)$ & 0.325 \\
\hline 7.BOH & $8(2.78 \%)$ & $5(1.71 \%)$ & 0.401 \\
\hline 8.Abnormal Presentation & $36(12.50 \%)$ & $38(12.97 \%)$ & \\
\hline $\begin{array}{l}\text { 9.0thers (Term pregnancy with } \\
\text { CPD in labor\& non progress of labor due } \\
\text { to other causes) }\end{array}$ & $35(12.15 \%)$ & $38(12.97 \%)$ & 0.838 \\
\hline
\end{tabular}


Table 4: Outcome according to maternal infectious complications

\begin{tabular}{|c|c|c|c|c|c|}
\hline Outcome & $\begin{array}{l}\text { Study } \\
\text { group A } \\
n=288\end{array}$ & $\begin{array}{l}\text { Control } \\
\text { group B } \\
n=293\end{array}$ & $\begin{array}{l}\text { Relative Risk } \\
95 \% \text { CI }\end{array}$ & $\begin{array}{l}\text { P Value (Mid- } \\
\text { P exact) }\end{array}$ & $\begin{array}{l}{ }^{* *} \text { CMLE OR } \\
95 \% \text { CI }\end{array}$ \\
\hline Cough & $20(6.94 \%)$ & $22(7.51 \%)$ & $\begin{array}{l}0.925 \\
(0.58 \text { to } 1.89)\end{array}$ & 0.846 & $\begin{array}{l}0.921 \\
(0.542 \text { to } \\
2.037)\end{array}$ \\
\hline Fever (2nd day) & $13(4.51 \%)$ & $17(5.80 \%)$ & 0.778 & $\begin{array}{l}0.557 \\
(0.345 \text { to } \\
1.786)\end{array}$ & $\begin{array}{l}0.735 \\
(0.321 \text { to } \\
1.756)\end{array}$ \\
\hline $\begin{array}{l}\text { Wound } \\
\text { indurations, } \\
\text { discharge, } \\
\text { erythema }\end{array}$ & $7(2.43 \%)$ & $17(5.80 \%)$ & $\begin{array}{l}0.419 \\
(0.176 \text { to } \\
0.994)\end{array}$ & 0.043 & $\begin{array}{l}0.405 \\
(0.154-0.974)\end{array}$ \\
\hline Endomyometritis & $3(1.04 \%)$ & $11(3.75 \%)$ & $\begin{array}{l}0.279 \\
(0.078 \text { to } \\
0.990)\end{array}$ & 0.036 & $\begin{array}{l}0.272 \\
(0.060 \text { to } \\
0.931)\end{array}$ \\
\hline
\end{tabular}

** CMLE= Conditional maximum likelihood estimate of Odds Ratio 
Table 5: Outcome according to neonatal complications

\begin{tabular}{|c|c|c|c|c|c|}
\hline Variable & $\begin{array}{l}\text { Study group } \\
\text { An=288 }\end{array}$ & $\begin{array}{l}\text { Control group } \\
\text { B n=293 }\end{array}$ & RR $(95 \%$ CI) & $\begin{array}{l}\text { P value } \\
\text { (Mid-P } \\
\text { exact) }\end{array}$ & $\begin{array}{l}\text { ** CMLE OR } \\
(95 \% \mathrm{CI})\end{array}$ \\
\hline Fever & $5(1.72 \%)$ & $6(2.05 \%)$ & $\begin{array}{l}0.849 \\
(0.220 \text { to } 3)\end{array}$ & 0.771 & $\begin{array}{l}0.811 \\
(0.215 \text { to } \\
3.052)\end{array}$ \\
\hline Sepsis & $11(3.82 \%)$ & $12(4.10 \%)$ & $\begin{array}{l}0.933 \\
(0.306 \text { to } \\
1.622)\end{array}$ & 0.412 & $\begin{array}{l}0.905 \\
(0.252 \\
\text { to1.632) }\end{array}$ \\
\hline Perinatal asphyxia & $3(1.04 \%)$ & $2(0.68 \%)$ & $\begin{array}{l}1.526 \\
(0.257 \text { to } \\
9.064)\end{array}$ & 0.673 & $\begin{array}{l}1.53 \\
(0.226 \text { to } \\
12.95)\end{array}$ \\
\hline Poor feeding & $5(1.74 \%)$ & $4(1.36 \%)$ & $\begin{array}{l}1.272 \\
(0.345 \text { to } \\
4.688)\end{array}$ & 0.733 & $\begin{array}{l}1.276 \\
(0.32 \text { to } 5.39)\end{array}$ \\
\hline Hyperbilirubinemia & $9(3.12 \%)$ & $10(3.41 \%)$ & $\begin{array}{l}0.916 \\
(0.39 \text { to } \\
3.164)\end{array}$ & 0.785 & $\begin{array}{l}0.905 \\
(0.412 \text { to } \\
3.436)\end{array}$ \\
\hline NICU Admission & $29(10.07 \%)$ & $31(10.58 \%)$ & $\begin{array}{l}0.952 \\
(0.582 \text { to } \\
1.548)\end{array}$ & 0.837 & $\begin{array}{l}0.944 \\
(0.545 \text { to } \\
1.631)\end{array}$ \\
\hline
\end{tabular}

** CMLE= Conditional maximum likelihood estimate of Odds

Table 6: Duration of staying at hospital of mothers\& NICU of babies

\begin{tabular}{|lllll|}
\hline & $\begin{array}{l}\text { Study group A } \\
\mathrm{n}=288\end{array}$ & $\begin{array}{l}\text { Control group B } \\
\mathrm{n}=293\end{array}$ & $\begin{array}{l}\text { P value } \\
\text { (Mid-P exact) }\end{array}$ & $\begin{array}{l}\text { 95\% CI } \\
\text { Of difference }\end{array}$ \\
$\begin{array}{l}\text { Maternal Stay } \\
\text { in days } \\
\text { Mean } \pm \text { SD }\end{array}$ & $4.36 \pm 1.15$ & $4.66 \pm 1.63$ & 0.010 & -0.529 to -0.070 \\
$\begin{array}{l}\text { Stay in NICU } \\
\text { in days } \\
\text { (Mean } \pm \text { SD) }\end{array}$ & $5.65 \pm 3.61$ & $5.77 \pm 3.86$ & 0.901 & -2.050 to 1.810 \\
\hline
\end{tabular}

